\title{
Protection against Schistosoma mansoni infection using a Fasciola hepatica-derived fatty acid binding protein from different delivery systems
}

Belén Vicente ${ }^{1}$, Julio López-Abán ${ }^{1 *}$, Jose Rojas-Caraballo ${ }^{1,3,4}$, Esther del Olmo², Pedro Fernández-Soto ${ }^{1}$ and Antonio Muro ${ }^{1}$

\begin{abstract}
Background: Schistosomiasis is a water-borne disease afflicting over 261 million people in many areas of the developing countries with high morbidity and mortality. The control relies mainly on treatment with praziquantel. Fatty acid binding proteins (FABP) have demonstrated high levels of immune-protection against trematode infections. This study reports the immunoprotection induced by cross-reacting Fasciola hepatica FABP, native (nFh12) and recombinantly expressed using two different expression systems Escherichia coli (rFh15) and baculovirus (rFh15b) against Schistosoma mansoni infection.
\end{abstract}

Methods: BALB/c mice were vaccinated with native $\mathrm{nFh} 12$ or recombinant $\mathrm{rFh} 15$ and $\mathrm{rFh} 15$ FABP from F. hepatica formulated in adjuvant adaptation (ADAD) system with natural or chemical synthesised immunomodulators (PAL and AA0029) and then challenged with 150 cercariae of S. mansoni. Parasite burden, hepatic lesions and antibody response were studied in vaccination trials. Furthermore differences between rFh15 and rFh15b immunological responses (cytokine production, splenocyte population and antibody levels) were studied.

Results: Vaccination with nFh12 induced significant reductions in worm burden (83 \%), eggs in tissues (82-92 \%) and hepatic lesions (85\%) compared to infected controls using PAL. Vaccination with rFh15 showed lower total worm burden (56-64\%), eggs in the liver (21-61\%), eggs in the gut (30-77\%) and hepatic damage (67-69\%) using PAL and AA0029 as immunomodulators. In contrast, mice vaccinated with rFh15b showed only reductions in eggs trapped in the liver and intestine (53 and $60 \%$, respectively), and hepatic lesions (45\%). We observed a significant rise in TNFa, IL-6, IL-2, IL-4 and high antibody response (IgG, IgG1, IgG2a, IgM and IgE) in mice immunised with either rFh15 or rFh15b. Moreover, mice immunised with rFh15b showed an increase in IFNy and a decrease in B220 cells compared to untreated mice, and less production of IgG1 and IgM than in mice immunised by rFh15.

Conclusions: Higher level of protection is obtained by using Fasciola hepatica-derived FABP protein against Schistosoma mansoni infection. Native FABP is more effective than both recombinant systems. It could be due to posttranslational modifications or FABP isoform or changes in the recombinant proteins.

Keywords: Schistosoma mansoni, Fasciola hepatica, PAL, AA0029, Fatty acid binding protein, Vaccines against helminths

\footnotetext{
* Correspondence: jlaban@usal.es

${ }^{1}$ Parasite and Molecular Immunology Laboratory, Tropical Disease Research Centre, Universidad de Salamanca (IBSAL-CIETUS), Avda. Licenciado Méndez Nieto s/n, 37007 Salamanca, Spain

Full list of author information is available at the end of the article
} 


\section{Background}

The blood flukes Schistosoma mansoni, S. haematobium and $S$. japonicum are the main causative agents of schistosomiasis in humans in Africa, Asia and South America. The Word Health Organisation (WHO) estimated that 261 million people living in 78 countries required treatment in 2013, of whom 121 million were school-aged children and $92 \%$ lived in Africa [1]. Presently, the main strategy against schistosomiasis involves the use of praziquantel to reduce worm burden and morbidity due to its high efficacy, affordable cost, operational convenience and limited side effects [2]. However high rates of reinfection and the reduced susceptibility of schistosomula leads to sub-optimal cure rates. After decades of continuous treatment, the concern of resistant linage selection or spreading of native tolerant strains is an important threat [3]. The use of artemisinin derivatives and combinations with praziquantel could improve cure rate in endemic areas [4, 5]. Many researchers believe that immunoprophylaxis could be a promising tool together with chemotherapy, safe water supply, adequate sanitation, hygiene education or snail control [6]. Reduction of parasite burden, amelioration of pathology and blocking of transmission are considered desirable features of the vaccine [7]. The basis of vaccine use against schistosomes is demonstrated by the partial resistance developed against natural infection and the high protection induced by irradiated cercariae reaching worm reductions of $41-75 \%$ depending on the total number of immunising parasites [8].

A plethora of proteins have been proposed as potential vaccines against schistosomiasis discovered by different methods: cDNA library screening with sera raised against whole or fractions of schistosomes, PCR amplification from a cDNA library, identification of membrane protein signal sequences, and mining the genome to identify membrane or secretory proteins by reverse vaccinology [9-11]. Only a small number of vaccines have reached Phase I clinical trials and only the glutathione-S transferase rSh28GST (Bilhvax) have reached Phase III against urinary schistosomiasis [12]. Fatty acid binding proteins (FABP) in trematodes are a family of proteins with isoforms in parenchymal and tegument cells. They are involved in cholesterol and long chain fatty acid uptake and transport, triclabendazole binding [13], antioxidant activity, immunomodulation [14]. Classical and non-classical such as exosomes secretory pathways were described [15]. The protein Sm14 from S. mansoni, derived from a cloned gene exhibited affinity to fatty acids and was able to protect outbreed mice and rabbits against the challenge with $S$. mansoni cercariae. Further research led to application of Pichia pastoris expression and the use of the synthetic adjuvant GLA-SE, which has been utilised in Phase I clinical trials [16]. Also,
Sm14 shows a $44 \%$ identity with rFh15 from Fasciola hepatica [17]. Identical basic three-dimensional structure and shared discontinuous epitopes were observed. Moreover, Sm14 induces abolition of liver damage in mice, sheep and goats against experimental infection with $F$. hepatica $[16,18,19]$. The native nFh12 and the recombinant rFh15 FABP from $F$. hepatica have shown protection in terms of reduction of worm burden and liver lesions using Freund's adjuvant in C57/BL6 mice against $S$. bovis infection [20, 21]. Moreover, large parasite burden reduction, liver lesion amelioration and antifecundity effects were observed in BALB/c mice and golden hamsters vaccinated with the rFh15 using the ADAD (adjuvant adaptation) vaccination system against S. bovis $[22,23]$. Furthermore, a FABP of $14.6 \mathrm{kDa}$ purified from Fasciola gigantica has proved reductions in parasite counts and liver lesions against S. mansoni infection in CD1 mice [24]. New expression systems are needed to allow a better conservation of post-translational modifications than in prokaryotic production systems. The baculovirus-based expression system is a safe, versatile and powerful cloning tool for production of recombinant proteins in eukaryotic cells that could be interesting to test against $S$. mansoni challenge and study the immunological response $[25,26]$.

Immunity adjuvants are recognised to have crucial importance in vaccine development. Adjuvant adaptation (ADAD) vaccination systems was developed as an alternative to Freund's adjuvant, which has side effects that limit its use in commercial vaccines, in vaccination against trematodes such as $F$. hepatica and schistosomes [27]. ADAD combines the antigen together with nonhaemolytic saponins from Quillaja saponaria and a natural or synthetic immunomodulator, forming an emulsion with the non-mineral oil Montanide ISA 763AVG to obtain a long-term delivery system [27]. The natural immunomodulator PAL is a hydroalcoholic extract from the rhizome of the fern Phlebodium pseudoaureum, that is able to down-regulate the Thresponse in mice immunised with Anisakis simplex, Trichinella spiralis and F. hepatica antigens [28]. The synthetic diamine AA0029 inhibits lymphoproliferation, modulates delayed-type hypersensivity in a $T$. spiralis model, modifies the ratios of $\mathrm{CD} 8+, \mathrm{CD} 4+$ and $\mathrm{MHC}$ Class II cells and increases nitric oxide production in LPS pre-stimulated rat alveolar macrophages [29]. Experiments using 14-3-3 protein from $S$. bovis, and FABP from $F$. hepatica formulated in ADAD system have yielded high protection in terms of parasite burden and liver damage [22, 23, 30].

The aim of this study is to examine the immunoprophylactic properties of three FABP from $F$. hepatica (nFh12, rFh15 and rFh15b) using the ADAD vaccination system against $S$. mansoni infection in BALB/c mice. 
Also immunological response to immunisation is studied using one recombinant obtained in Escherichia coli (rFh15) and one produced in baculovirus-transformed Trichoplusia ni caterpillars (rFh15b).

\section{Methods}

Animals, ethics statement and parasites

Animal procedures used in this study complied with the Spanish (L32/2007, L6/2013 and RD53/2013) and the European Union (Directive 2010/63/EU) regulations on animal experimentation. The Ethics Committee of the University of Salamanca (Spain) approved procedures used in the present study (protocol 48531). SPF female CD1 and BALB/c mice obtained from Charles River (Lyon, France) weighing 19-26 g used in this work were maintained in a temperature and humidity controlled environment with a $12 \mathrm{~h}$ light/dark cycle and provided with water and food ad libitum at the animal experimentation facilities of the University of Salamanca. The animals' health status was monitored throughout the experiments by a health surveillance program according to the guidelines of the Federation of European Laboratory Animal Science Associations (FELASA). Mice were humanely euthanised with an intraperitoneal injection of pentobarbital $(100 \mathrm{mg} / \mathrm{kg})$, according to protocols supplied by the animal facilities of the University of Salamanca at the end of the experimental procedures or when any deterioration of mice health status was evidenced. Size of groups was calculated by power analysis using "size.fdr" package in $\mathrm{R}$ and following the 3Rs recommendations $[31,32]$. All efforts were made to minimise suffering. LE strain of $S$. mansoni was maintained in our laboratory in Biomphalaria glabrata snails as intermediate hosts and CD1 mice as definitive hosts. The number of cercariae and their viability were determined using a stereoscopic microscope.

\section{S. mansoni soluble adult worm antigen and $F$. hepatica native $\mathrm{nFh} 12$ purification}

Soluble adult worm antigens from S. mansoni (SoSmAWA) used for ELISA were prepared as previously described [20]. Twenty adult worms were suspended in $1 \mathrm{~mL}$ of sterile phosphate-buffered saline (PBS) containing $1 \mathrm{mM}$ phenyl methyl sulphonyl fluoride (PMSF; Sigma, St Louis, MO), homogenised, frozen and thawed thrice and then sonicated thrice $(70 \mathrm{kHz})$ for 1 min each. The suspension was centrifuged at 20,000 g for $30 \mathrm{~min}$ at $4{ }^{\circ} \mathrm{C}$. Native $12 \mathrm{kDa}$. hepatica antigen (nFh12) was purified as described by Hillyer [17] by a combination of gel filtration using Sephadex G-50 and two-step isoelectric focusing runs with 3-10 and 4-6 ampholytes. A one dimension SDS-PAGE was performed to confirm there was a single band and a rabbit monospecific, polyclonal anti-nFh12 antiserum was used in SDS-PAGE and immunoblot to confirm that the purified polypeptide was $n$ Fh12.

\section{Recombinant $\mathrm{rFh} 15$ and $\mathrm{rFh} 15 \mathrm{~b}$ protein expression and purification}

The recombinant fatty-acid binding proteins from $F$. hepatica were produced using two different expression systems. The first was based on the use of E. coli BL21 bacteria (rFh15). The recombinant protein was manufactured following Rodríguez-Pérez et al. [33]. Briefly, total RNA from one $F$. hepatica adult worm was isolated and used for cDNA synthesis. The rFh15 gene (GenBank M95291.1) was amplified using the following primer sequences: forward 5'-GGA TCC ATG GCT GAC TTT GTG GG-3' and reverse 5' -CTC GAG CGC TTT GAG CAG AGT G-3' and restriction sites for BamHI and $X$ XoI were added. PCR products were then purified and cloned into pGEX-4T2 vector with a $S$. japonicum glutathione $\mathrm{S}$-transferase sequence for further detection and purification. The resulting recombinant DNA plasmid was purified and sequenced to verify the integrity of the cloned insert. Transformed E. coli BL21 cells were grown in Luria Bertani medium with ampicillin until reaching an optical density of 0.6 and then induced by the addition of isopropyl $\beta$-tiogalactopyranoside (IPTG) at a final concentration of $1 \mathrm{mM}$. The cell pellet was recovered by centrifugation of the culture at $18000 \mathrm{~g}$ for 30 min, suspended in PBS with $1 \mathrm{mM}$ PMSF and $1 \%$ Triton X-100 sonicated and centrifuged. Solubilised protein was purified by affinity chromatography with a glutathione Sepharose 4B resin. Non-retained proteins were eluted with PBS whilst rFh15 was eluted by addition of PBS plus thrombin. Non-retained proteins were eluted with PBS whilst the recombinant protein was cleaved to obtain rFh15 by adding 50 units of thrombin (Amersham Biosciences) in PBS. Fractions were analysed by SDS-PAGE and proteins quantified by using a Micro BCA Protein Assay Kit.

The second method to obtain the recombinant rFh15 protein was based on the use of a baculovirus expression vector system, using standardised protocols of ALGENEX (Madrid, Spain). Briefly, to clone into pFasBacHis vector a nucleotide sequence from $15 \mathrm{kDa}$ FABP protein (GenBank M95291.1) was synthesised and a Kozak sequence was inserted into the $\mathrm{N}$-terminus extreme, along with $B a m H I$ and $X b a \mathrm{I}$ restriction sites at the $\mathrm{N}$ - and $\mathrm{C}$ terminus respectively. The plasmid pMA (ampR) with the cloned Fh15 gene between $\mathrm{KpnI} / \mathrm{Sacl}$ sites was used to amplify DNA by transformation of E. coli (DH5alpha) cells and isolation of ampicillin-resistant colonies. The resulting amplified DNA together with the cloning vector (pFasBacHis) were cut with restriction enzymes $\mathrm{BamHI}$ and $\mathrm{Xbal}$ and the corresponding band (412 bp) from Fh15 insert was isolated and 
purified. pFasBacHis vector was dephosphorylated with alkaline phosphatase treatment and the Fh15 insert was subsequently ligated. The resulting product was then used to transform E. coli (DH5alpha) cells and ampicillin- and gentamicin-resistant colonies were then isolated. The DNA from these isolated colonies was isolated and characterised using the restriction enzymes for BamHI and Xbal sites, respectively, and automated sequence was performed to verify the sequence of the insert. The resulting vector and the sequence of the Fh15 insert is depicted in Fig. 1a. To obtain the recombinant baculovirus, E. coli special competent (DH10B) cells were transformed starting from a previously generated vector (pFBFh15His). These cells carry the receptor bMON14272 that contains a beta-galactosidase codifying gene. Upon incorporation in the same cell vector and receptor, the recombinant baculovirus presents resistance to kanamycin, tetracyclin and geneticin and loses its beta-galactosidase activity. One colony resistant to the three antibiotics was selected and the DNA was isolated and used to transfect insect cells sf21 using the cellfectin reagent (Invitrogen, Waltham, MA USA). Seventy-two hours after the transfection, the so-called progeny 1 from the recombinant baculovirus was collected and stored until further use. Finally, thirty Trichoplusia $n i$ larvae were inoculated with the previously obtained recombinant virus. Larvae were harvested during the next 48-96 $\mathrm{h}$ and the expression of the recombinant protein was assessed using both Coomassie blue staining and Western blot with monoclonal anti-6His antibodies.

\section{ADAD vaccination system}

The rFh15 protein was formulated in a micelle composed of non-haemolytic saponins from Quillaja saponaria (Qs; Sigma, St Louis, Missouri, USA) and natural (PAL) or synthetic aliphatic diamine (AA0029) as

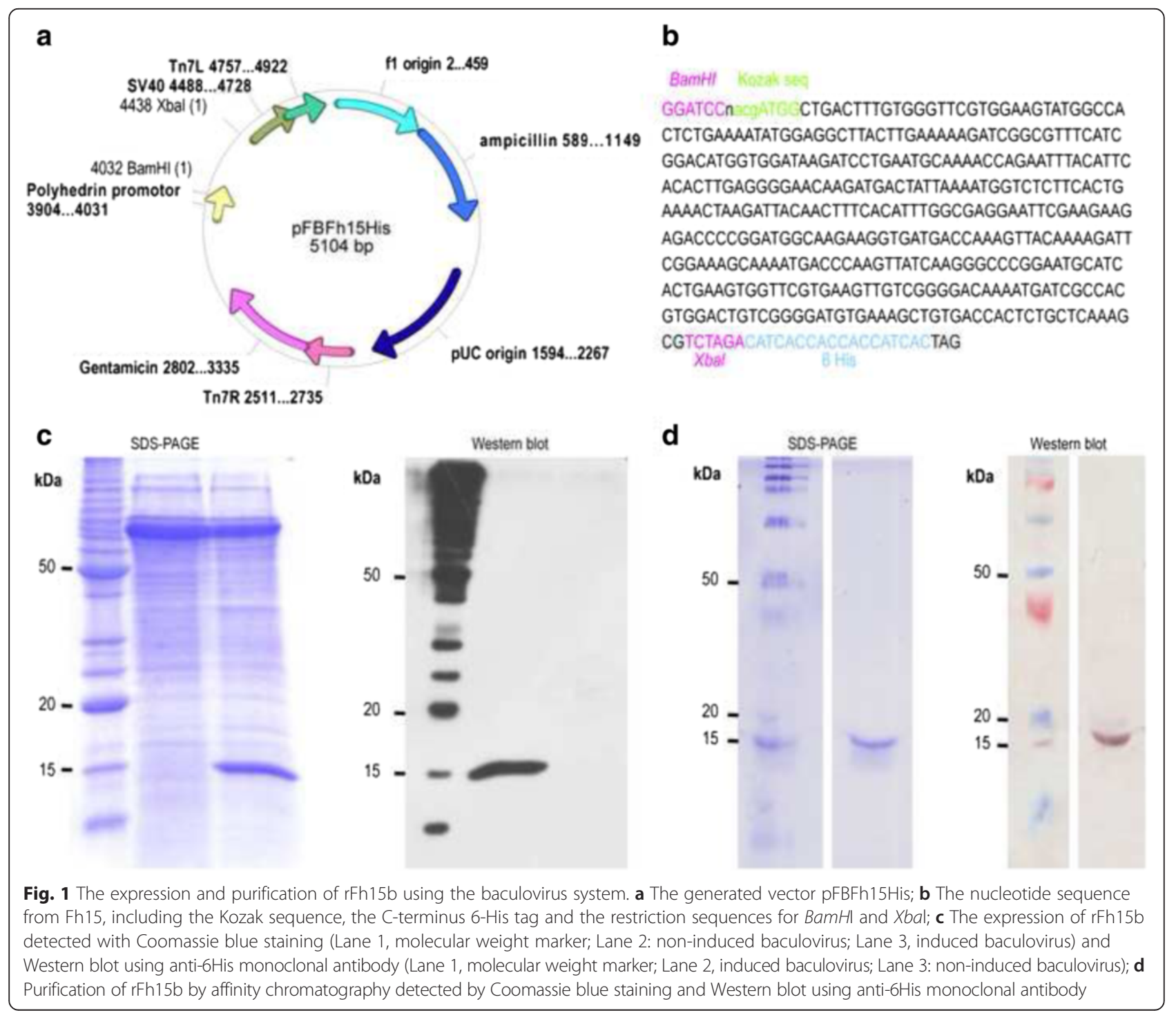


immunomodulator. Thereafter, this micelle was emulsified in a non-mineral oil (Montanide ISA763A, SEPPIC, Paris, France) at an oil/water ratio of 70/30 and subcutaneously injected into $\mathrm{BALB} / \mathrm{c}$ mice. The ADAD vaccination system consists of a set of two subcutaneous injections. The first injection, called "Adaptation", contains Qs and PAL or AA0029 emulsified in the non-mineral oil. The second injection, administered 5 days after the adaptation, contains the rFh15 antigen with Qs and PAL or AA0029 in the emulsion oil. Individual doses per injection included in each case were as follows: $20 \mu \mathrm{g}$ of Qs, $600 \mu \mathrm{g}$ of PAL or $100 \mu \mathrm{g}$ of AA0029, and $10 \mu \mathrm{g}$ of nFh12, rFh15 or rFh15b, resulting in a final volume of a $200 \mu \mathrm{l}$ injection of emulsion in the non-mineral oil $[22,30]$.

\section{Vaccination experiment schedules}

BALB/c mice were randomly allocated in groups of nine animals each as follows: Untreated and uninfected; $S$. mansoni infected; Control adjuvant (injected with ADAD with Qs and the natural immunomodulator PAL or the synthetic AA0029) and Vaccinated groups (vaccinated with ADAD with the corresponding FABP nFh12, rFh15 or rFh15b formulated with the corresponding immunomodulator PAL or AA0029 and infected). Two weeks after the first immunisation animals were boosted with the same doses. Two weeks after the second immunisation, each mouse was exposed to 150 cercariae of S. mansoni for $45 \mathrm{~min}$. Eight weeks post-infection all mice were euthanised with intraperitoneal injection of sodium pentobarbital $(100 \mathrm{mg} / \mathrm{kg})$ and then perfused by intra-cardiac injection of PBS plus heparin, and the number of $S$. mansoni adult worms recovered from the portal and mesenteric veins was recorded. In addition, the number of parasite eggs in the liver and intestine was counted using a McMaster camera after digestion with $25 \mathrm{ml}$ of $5 \% \mathrm{KOH}$ for $16 \mathrm{~h}$ at $37{ }^{\circ} \mathrm{C}$ with gentle shaking. Macroscopic lesions of the liver were quantified as granuloma-affected surface per $100 \mathrm{~mm}^{2}$ in each mouse using ImageJ $1.45 \mathrm{~s}$ software [34]. Protection percentage was calculated for all parasitological and pathological magnitudes as follows: (mean in the infected control group - mean in experimental group) $\times 100$ / mean in infected control group. Blood samples were collected from each animal before immunisation, infection and necropsy for humoral immune response studies.

\section{Specific antibody response against FABP and SoSmAWA} Specific anti-rFh15 or anti-SoSmAWA antibody profiles were measured using an indirect ELISA as described by Abán et al. [20]. Briefly, 96-well polystyrene plates (Costar) were coated with $2.0 \mu \mathrm{g}$ of $\mathrm{nFh} 12, \mathrm{rFh} 15, \mathrm{rFh} 15 \mathrm{~b}$ or $2.5 \mu \mathrm{g}$ of SoSmAWA antigen for $12 \mathrm{~h}$ in carbonate buffer ( $\mathrm{pH}$ 9.0) and then blocked with $2 \%$ bovine serum albumin in PBS. Sera were then added at 1:100 dilutions and incubated for
$1 \mathrm{~h}$ at $37^{\circ} \mathrm{C}$, followed by the addition of goat peroxidaselabelled anti-mouse IgG, IgG1, IgG2a, IgM or IgE antibodies at 1:1000 dilution (Sigma, St. Louis, MO, USA). The reaction was developed with $\mathrm{H}_{2} \mathrm{O}_{2}$ and ortophenilenediamine (OPD, Sigma) in citrate buffer (pH 5.0) and absorbance was measured at $492 \mathrm{~nm}$ with an Ear400FT ELISA reader (Lab Instruments, Groding, Austria).

\section{Immune response in $B A L B / c$ mice immunised with the recombinant FABP rFh15 and rFh15b}

Four groups of six female BALB/c each were used for the characterisation of immunological response: Untreated; Injected with ADAD only with AA0029+Qs as adjuvant control; Immunised with rFh15 formulated in ADAD system with AA0029 (AA0029+Qs+rFh15); and Immunised with rFh15b formulated in ADAD system with AA0029 (AA0029+Qs+rFh15b). Mice were immunised and two booster doses were given after 2 and 4 weeks, respectively. Two weeks after the immunisation schedule all mice were anesthetised with isoflurane and euthanised by cervical dislocation. Spleens were then aseptically removed for obtaining splenocytes by perfusion with sterile PBS to study cytokine profile and to quantify T-cell subpopulations. Blood samples were collected for antibody detection from the animals before each immunisation and at the necropsy.

\section{Cytokine measurement}

Splenocytes obtained from individual mice were cultured in a 6 -well plate at $1 \times 10^{6}$ cells per well in a complete RPMI 1640 medium containing $10 \%$ heat-inactivated foetal calf serum, $5 \mathrm{mM}$ L-glutamine and antibiotics: 100 units $/ \mathrm{ml}$ penicillin and $100 \mu \mathrm{g} / \mathrm{ml}$ streptomycin as previously described [35]. Cells were in vitro stimulated with rFh15 or rFh15b at a final concentration of $10 \mu \mathrm{g} / \mathrm{ml}$ for $72 \mathrm{~h}$ at $37{ }^{\circ} \mathrm{C}$ in a humidified atmosphere with $5 \%$ $\mathrm{CO}_{2}$. Culture supernatants were recovered for cytokines determination. Splenocytes belonging to untreated mice were used as controls. A flow cytometry-based technique was used for interferon $\gamma$ (IFN $\gamma$ ), tumor necrosis factor $\alpha$ (TNF $\alpha$ ), interleukin (IL) $1 \alpha$, IL-2, IL-4, IL-6, IL-10 and IL17 quantitation in each of the groups of mice used in this study. The FlowCytomix Mouse Th1/Th2 10plex kit (Bender MedSystems GmbH, Vienna, Austria) was used according to the manufacturer's instructions. Briefly, different size fluorescent beads, coated with capture antibodies specific for the aforementioned cytokines, were incubated with mouse splenocyte samples and with biotin-conjugated secondary antibodies for $2 \mathrm{~h}$ at room temperature. The specific antibodies bound to the analytes captured by the first antibodies. After washing the tubes with PBS plus $2 \%$ foetal calf serum, Streptavidin-Phycoerythrine (S-PE) solution was added and incubated at room temperature for $1 \mathrm{~h}$. S-PE binds to the biotin conjugate and emits fluorescent signals. Flow cytometry data was collected using a 
FACSCalibur flow cytometer (BD Biosciences, Franklin Lakes, NJ, USA) at the University of Salamanca's Flow Cytometry Central Service; 8000 events were collected (gated by forward and side scatter) and data was analysed using FlowCytomix Pro 3.0 software (Bender MedSystems, Vienna, Austria). Each cytokine concentration was determined from standard curves using known mouse recombinant cytokine concentrations.

\section{Flow cytometry analysis of splenic B and T-cell populations}

Splenocytes from untreated, AA0029+Qs-treated, rFh15immunised and rFh15b-immunised mice were incubated with the blocking anti-CD16/CD32 monoclonal antibody for $5 \mathrm{~min}$ at room temperature and stained with commercial fluorochrome-conjugated antibodies at 1/50 dilution in PBS plus $2 \%$ foetal calf serum for $30 \mathrm{~min}$ at $4{ }^{\circ} \mathrm{C}$. Rat anti-mouse CD45-peridinin chlorophyll protein (PerCP)- cyanine dye (Cy5.5), CD4-fluorescein isothyosanate (FITC), CD8-phycoerythrin (PE), CD45R/B220allophycocyanin (APC), CD197-PE (CCR7), CD62L-APC and hamster anti-mouse CD27 APC (BD Pharmingen, USA) were used. After incubation, cells were washed in PBS with $2 \%$ foetal calf serum and centrifuged at $1000 \mathrm{~g}$ for $5 \mathrm{~min}$ and the supernatant was then discarded. The cells were fixed with $100 \mu \mathrm{l}$ of a $2 \%$ paraformaldehyde solution for $1 \mathrm{~h}$ at $4{ }^{\circ} \mathrm{C}$. Phenotypic analyses were performed in a FACScalibur flow cytometer. Data were collected on 30,000 events (gated by forward and side scatter) and analysed using Gatelogic Flow Cytometry Analysis Software (INIVAI technologies Pty Ltd).

\section{Statistical analysis}

The results were expressed as the mean \pm standard error of the mean (SEM). Normal distribution of data was assessed by Kolmogorov-Smirnov test and homogeneity of variance was tested by Barrett test. Significant differences among groups were found using one-way ANOVA test and post-hoc Tukey's honest significance tests (HSD) or Kruskal-Wallis (K-W) test. All statistical analyses were considered significant at $P<0.05$. SPSS 21 software (IBM) was used for data analysis.

Table 1 Protection levels (\% of reduction, R) in worm recovery (total counts, females and males), hepatic damage extension (mm²/ $100 \mathrm{~mm}^{2}$ ) and number of eggs per gram (EPG) in the tissues in vaccinated BALB/c mice using natural and recombinant FABP (nFh12, rFh15 or rFh15b) formulated with the adjuvant adaptation (ADAD) vaccination system with the natural immunomodulator PAL or the synthetic AA0029. Data presented as the mean \pm standard error of the mean. ANOVA F- and P-values, and post-hoc Tukey's honest significance test $P$ values of significant increases are included

\begin{tabular}{|c|c|c|c|c|c|c|c|c|c|c|c|c|}
\hline Groups & $\begin{array}{l}\text { Total worms } \\
(\text { mean } \pm \text { SEM })\end{array}$ & $\begin{array}{l}\mathrm{R} \\
(\%)\end{array}$ & $\begin{array}{l}\text { Females } \\
(\text { mean } \pm \text { SEM })\end{array}$ & $\begin{array}{l}\mathrm{R} \\
(\%)\end{array}$ & $\begin{array}{l}\text { Males } \\
(\text { mean } \pm \text { SEM })\end{array}$ & $\begin{array}{l}\mathrm{R} \\
(\%)\end{array}$ & $\begin{array}{l}\text { Hepatic lesion } \\
(\text { mean } \pm \text { SEM) }\end{array}$ & $\begin{array}{l}\mathrm{R} \\
(\%)\end{array}$ & $\begin{array}{l}\text { EPG in liver } \\
(\text { mean } \pm \text { SEM })\end{array}$ & $\begin{array}{l}\mathrm{R} \\
(\%)\end{array}$ & $\begin{array}{l}\text { EPG intestine } \\
\text { (mean } \pm \text { SEM) }\end{array}$ & $\begin{array}{l}\mathrm{R} \\
(\%)\end{array}$ \\
\hline \multicolumn{13}{|l|}{ Experiment 1} \\
\hline Infected & $36.3 \pm 4.9$ & - & $19.7 \pm 2.9$ & - & $16.6 \pm 2.0$ & - & $64.1 \pm 7.1$ & - & $17,432 \pm 3,586$ & - & $14,812 \pm 3,934$ & - \\
\hline$P A L+Q s$ & $23.4 \pm 2.5$ & 36 & $12.4 \pm 1.4$ & 37 & $11.1 \pm 1.0$ & 33 & $74.4 \pm 6.4$ & $N R$ & $16,551 \pm 2,620$ & 5 & $17,367 \pm 2,277$ & NR \\
\hline $\mathrm{PAL}+\mathrm{Qs}+\mathrm{nFh} 12$ & $\begin{array}{l}6.0 \pm 1.7 \\
P<0.001^{a}\end{array}$ & 83 & $\begin{array}{l}3.6 \pm 1.0 \\
P<0.001^{a}\end{array}$ & 82 & $\begin{array}{l}2.1 \pm 0.8 \\
P<0.001^{a}\end{array}$ & 87 & $\begin{array}{l}9.4 \pm 3.0 \\
P<0.001^{a}\end{array}$ & 85 & $\begin{array}{l}3,089 \pm 1,001 \\
P=0.001^{a}\end{array}$ & 82 & $\begin{array}{l}1,186 \pm 523 \\
P<0.001^{a}\end{array}$ & 92 \\
\hline ANOVA & $\begin{array}{l}F_{(2,24)}=23.39 \\
P<0.001\end{array}$ & & $\begin{array}{l}F_{(2,24)}=18.49 \\
P<0.001\end{array}$ & & $\begin{array}{l}F_{(2,24)}=30.13 \\
P<0.001\end{array}$ & & $\begin{array}{l}F_{(2,24)}=39.41 \\
P<0.001\end{array}$ & & $\begin{array}{l}F_{(2,24)}=10.27 \\
P<0.001\end{array}$ & & $\begin{array}{l}F_{(3,32)}=16.31 \\
P<0.001\end{array}$ & \\
\hline \multicolumn{13}{|l|}{ Experiment 2} \\
\hline Infected & $49.0 \pm 6.1$ & - & $24.0 \pm 7.3$ & - & $25.0 \pm 8.8$ & - & $61.2 \pm 8.3$ & - & $18,008 \pm 2,362$ & - & $18,197 \pm 2,079$ & - \\
\hline$P A L+Q s$ & $31.6 \pm 3.4$ & 35 & $18.6 \pm 2.1$ & 22 & $13.5 \pm 1.2$ & 46 & $71.0 \pm 6.2$ & $N R$ & $17,098 \pm 2,706$ & 5 & $21,700 \pm 2,968$ & NR \\
\hline$P A L+Q s+r F h 15$ & $\begin{array}{l}21.8 \pm 2.5 \\
P=0.006^{\mathrm{a}}\end{array}$ & 56 & $\begin{array}{l}9.0 \pm 1.2 \\
P<0.001^{a}\end{array}$ & 63 & $\begin{array}{l}12.8 \pm 1.5 \\
P<0.001^{\mathrm{a}}\end{array}$ & 49 & $\begin{array}{l}18.7 \pm 2.2 \\
P<0.001^{a}\end{array}$ & 69 & $14,247 \pm 668$ & 21 & $12,724 \pm 488$ & 30 \\
\hline ANOVA & $\begin{array}{l}F_{(2,24)}=9.04 \\
P<0.001\end{array}$ & & $\begin{array}{l}F_{(2,24)}=13.80 \\
P<0.001\end{array}$ & & $\begin{array}{l}F_{(2,24)}=9.93 \\
P<0.001\end{array}$ & & $\begin{array}{l}F_{(2,24)}=18.37 \\
P<0.001\end{array}$ & & & & & \\
\hline \multicolumn{13}{|l|}{ Experiment 3} \\
\hline Infected & $34.5 \pm 6.9$ & - & $18.0 \pm 3.6$ & - & $16.5 \pm 3.4$ & - & $61.8 \pm 14.4$ & - & $9,986 \pm 2,360$ & - & $7,748 \pm 1,315$ & - \\
\hline AA0029+Qs & $42.5 \pm 8.0$ & $N R$ & $20.0 \pm 4.4$ & $N R$ & $22.5 \pm 3.9$ & $N R$ & $77.0 \pm 19.0$ & $N R$ & $13,242 \pm 1,597$ & $N R$ & $8,084 \pm 775$ & NR \\
\hline AA0029+Qs+rFh15 & $\begin{array}{l}12.5 \pm 3.8 \\
P=0.046^{\mathrm{a}}\end{array}$ & 64 & $\begin{array}{l}5.5 \pm 2.0 \\
P=0.011^{\mathrm{a}}\end{array}$ & 69 & $\begin{array}{l}7.0 \pm 2.0 \\
P=0.041^{a}\end{array}$ & 58 & $\begin{array}{l}20.6 \pm 14.0 \\
P=0.049^{a}\end{array}$ & 67 & $\begin{array}{l}3,872 \pm 1,814 \\
P=0.024^{a}\end{array}$ & 61 & $\begin{array}{l}1,800 \pm 730 \\
P=0.001^{a}\end{array}$ & 77 \\
\hline AA0029+Qs+rFh15b & $25.1 \pm 7.8$ & 27 & $\begin{array}{l}10.1 \pm 3.2 \\
P=0.021^{\mathrm{a}}\end{array}$ & 44 & $15.0 \pm 4.8$ & 9 & $\begin{array}{l}15.2 \pm 7.1 \\
P=0.048^{a}\end{array}$ & 75 & $\begin{array}{l}4,692 \pm 1,181 \\
P=0.035^{a}\end{array}$ & 53 & $\begin{array}{l}3,098 \pm 800 \\
P=0.001^{a}\end{array}$ & 60 \\
\hline ANOVA & $\begin{array}{l}F_{(3,32)}=3.09 \\
P=0.047\end{array}$ & & $\begin{array}{l}F_{(3,32)}=3.75 \\
P=0.026\end{array}$ & & $\begin{array}{l}F_{(3,32)}=2.97 \\
P=0.048\end{array}$ & & $\begin{array}{l}F_{(3,32)}=4.05 \\
P=0.007\end{array}$ & & $\begin{array}{l}F_{(3,32)}=4.25 \\
P=0.003\end{array}$ & & $\begin{array}{l}F_{(3,32)}=11.61 \\
P<0.001\end{array}$ & \\
\hline
\end{tabular}




\section{Results}

Recombinant expression and detection of antigens

Expression and purification of $F$. hepatica-derived native nFh12 and recombinant rFh15 proteins were previously reported [17]. Here, we used a baculovirus expression vector system that improves the production of recombinant proteins compared to the classical expression systems based on the use of bacteria or yeasts, which also retains recombinant proteins native configuration along the production and purification steps to produce a $F$. hepatica-derived FABP protein (Fig. 1a and 1b). Starting with $30 \mathrm{~T}$. ni larvae inoculated with recombinant virus, cells were recovered during the next 48-96 h to assess recombinant protein expression, which was confirmed using both Coomassie blue staining and western blot using anti-6His monoclonal antibody as shown in Fig. 1c. Coomassie blue staining detected a majority band with an estimated molecular weight of $15.7 \mathrm{kDa}$ in the crude extract. Specific detection with monoclonal antibody confirmed the presence of a single band with the same molecular weight. Upon detection, the recombinant protein was on-column purified by affinity chromatography using a Ni-NTA column (Fig. 1d). As depicted, a single band with a molecular weight of $15 \mathrm{kDa}$ was detected using Coomassie blue staining, coming from pooled column-retained fractions, dialysed against ammonium carbonate $(50 \mathrm{mM})$, lyophilised and resuspended in high-purity distilled water. Western blot from the same fraction also revealed the presence of a single band with the same molecular weight (Fig. 1d). Protein quantitation revealed the recovery of $5 \mathrm{mg}$ of pure recombinant protein.

\section{Vaccination with the native $\mathrm{nFh} 12$ formulated in ADAD} with PAL triggers protection against $S$. mansoni infection Significant reductions in recovered total worms (83\%), males (87 \%) and females (82 \%) were observed in BALB/c mice immunised with nFh12 formulated in ADAD with the natural immunomodulator PAL (PAL+Qs+nFh12) compared to the infected control group (Table 1). Also, a significant decrease in the number of eggs present in the liver (82\%) and in the intestine (92\%) were detected (Table 1). In concordance, hepatic damage extension was significantly reduced (85\%) compared to the infection control group (Table 1, Fig. 2). Furthermore, mice injected only with PAL+Qs did not show significant protection in

\section{Experiment 1}

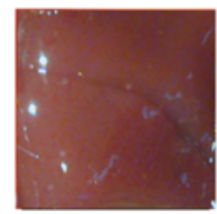

Uninfected

\section{Experiment 2}

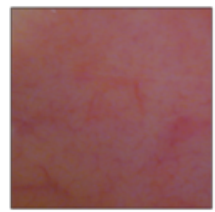

Uninfected

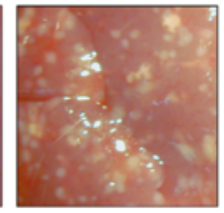

Infected

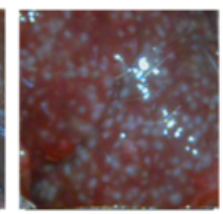

$P A L+Q s$

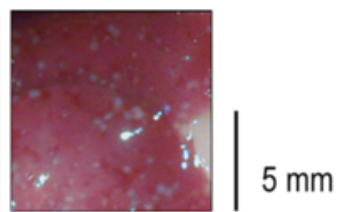

$\mathrm{PAL}+\mathrm{Qs}+\mathrm{nFh12}$

\section{Experiment 3}

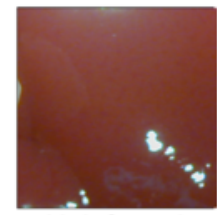

Uninfected

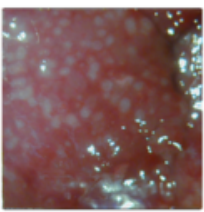

Infected

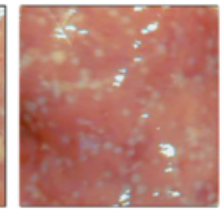

$P A L+Q s$

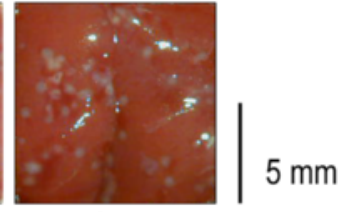

$P A L+Q s+r F h 15$

\section{$\mathrm{mm}$}

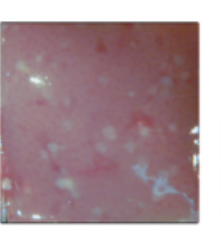

AA0029+Qs AA0029+Qs

+ rFh15 +rFh15b

Fig. 2 Representative hepatic lesion area reduction in BALB/c mice after vaccination. Natural and recombinant FABP (nFh12, rFh15 or rFh15b) formulated with the adjuvant adaptation (ADAD) vaccination system were used with the natural immunomodulator PAL or the synthetic AA0029 and challenged with 150 cercariae of S. mansoni in three separate experiments 
terms of parasite burden or hepatic lesions (Table 1). A significantly higher production of specific anti-nFh12 IgG was observed in the nFh12 vaccinated group compared to uninfected, infected or adjuvant controls after the second immunisation which remained until the end of the experiment (Fig. 3a and Additional file 1: Table S1). Also all infected groups showed a significant production of IgG, IgG1 8 weeks postinfection against SoSmAWA but only vaccinated with $\mathrm{PAL}+\mathrm{Qs}+\mathrm{nFh} 12$ showed significant IgG2a production (Fig. 4a and Additional file 2: Table S2).

\section{Vaccination with the recombinant $\mathrm{rFh} 15$ formulated with ADAD using PAL stimulates high protection against $S$. mansoni infection}

Mice vaccinated with $\mathrm{rFh} 15$ formulated in ADAD with the natural immunomodulator PAL (PAL+Qs+rFh15) induced significant reduction in worm burden $(56 \%$ in total worms, $63 \%$ in females and $49 \%$ in males) compared to infected controls (Table 1). Slight decreases in the number of eggs present in the liver $(21 \%)$ and the gut $(30 \%)$ of the vaccinated group were observed in comparison to infected group (Table 1). Moreover, in concordance with the reduction in worm burden, liver surface damage showed significant reduction (69 \%) compared to infected group (Table 1, Fig. 2b). Mice injected with PAL+Qs did not show significant reductions in parasite burden or hepatic lesions (Table 1). A significantly higher production of specific anti-rFh15 IgG, was observed in the rFh15 vaccinated group compared to the uninfected control group (Fig. 3b and Additional file 1: Table S1). Also all infected groups showed significant increase of IgG, IgG1 against SoSmAWA 8 weeks post-infection, but only groups vaccinated with $\mathrm{PAL}+\mathrm{Qs}+\mathrm{Fh} 15$ showed statisticaly significant IgG2a increase (Fig. $4 \mathrm{~b}$ and Additional file 2: Table S2).

Vaccination with $\mathrm{rFh} 15$ induces more protection than $\mathrm{rFh} 15 \mathrm{~b}$ against S. mansoni infection in BALB/c mice using ADAD vaccination system with the immunomodulator AA0029

Vaccination with $\mathrm{rFh} 15$ formulated in ADAD with the synthetic immunomodulator AA0029 (AA0029+Qs+rFh15) induces significant reduction of worm burden $(64 \%$ in total worms, $69 \%$ in females and $58 \%$ in males) in comparison with infected controls (Table 1). Also significant decreases in the number of eggs recovered from the liver $(61 \%)$ and gut $(77 \%)$ of the vaccinated group were observed in comparison with the infected group agreeing with the reduction in worm burden (Table 1). Moreover, there was a significant reduction $(67 \%)$ of liver surface damage in vaccinated mice compared to infected mice (Table 1, Fig. 2). Vaccination with rFh15b obtained from $T$. $n i$ larvae (AA0029+Qs+rFh15b) showed significant protection

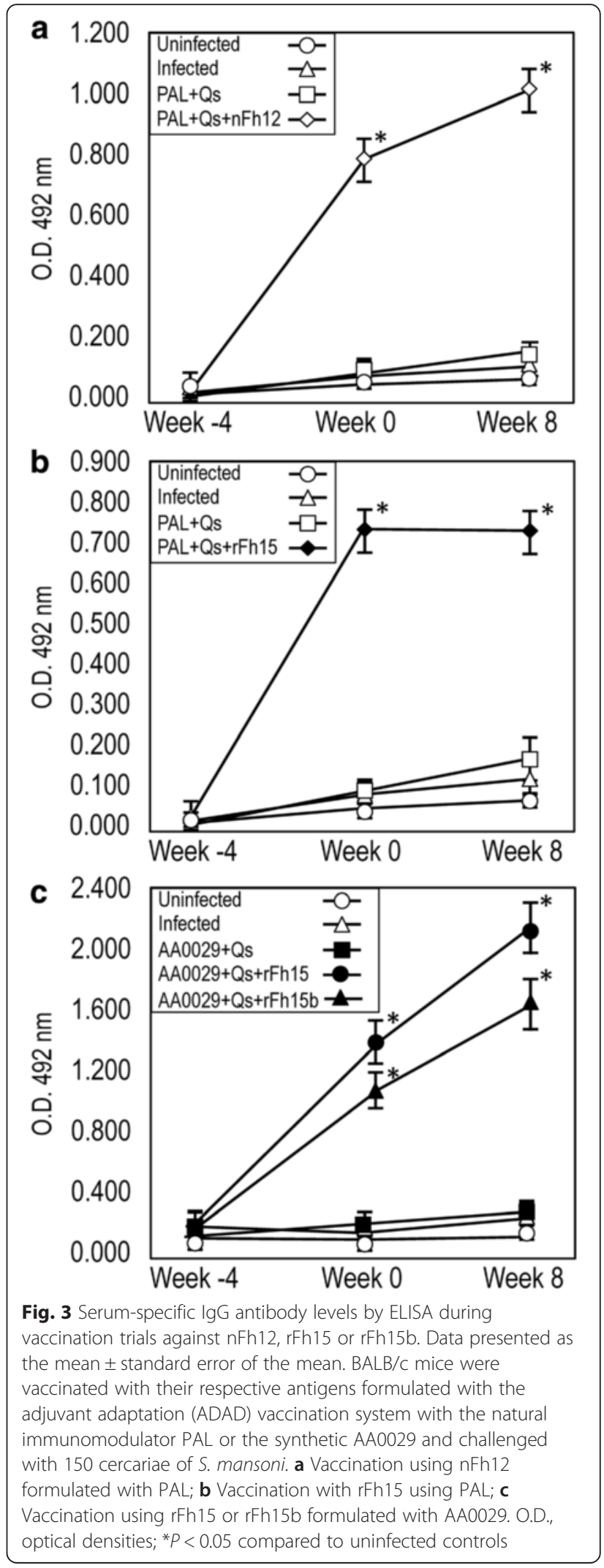




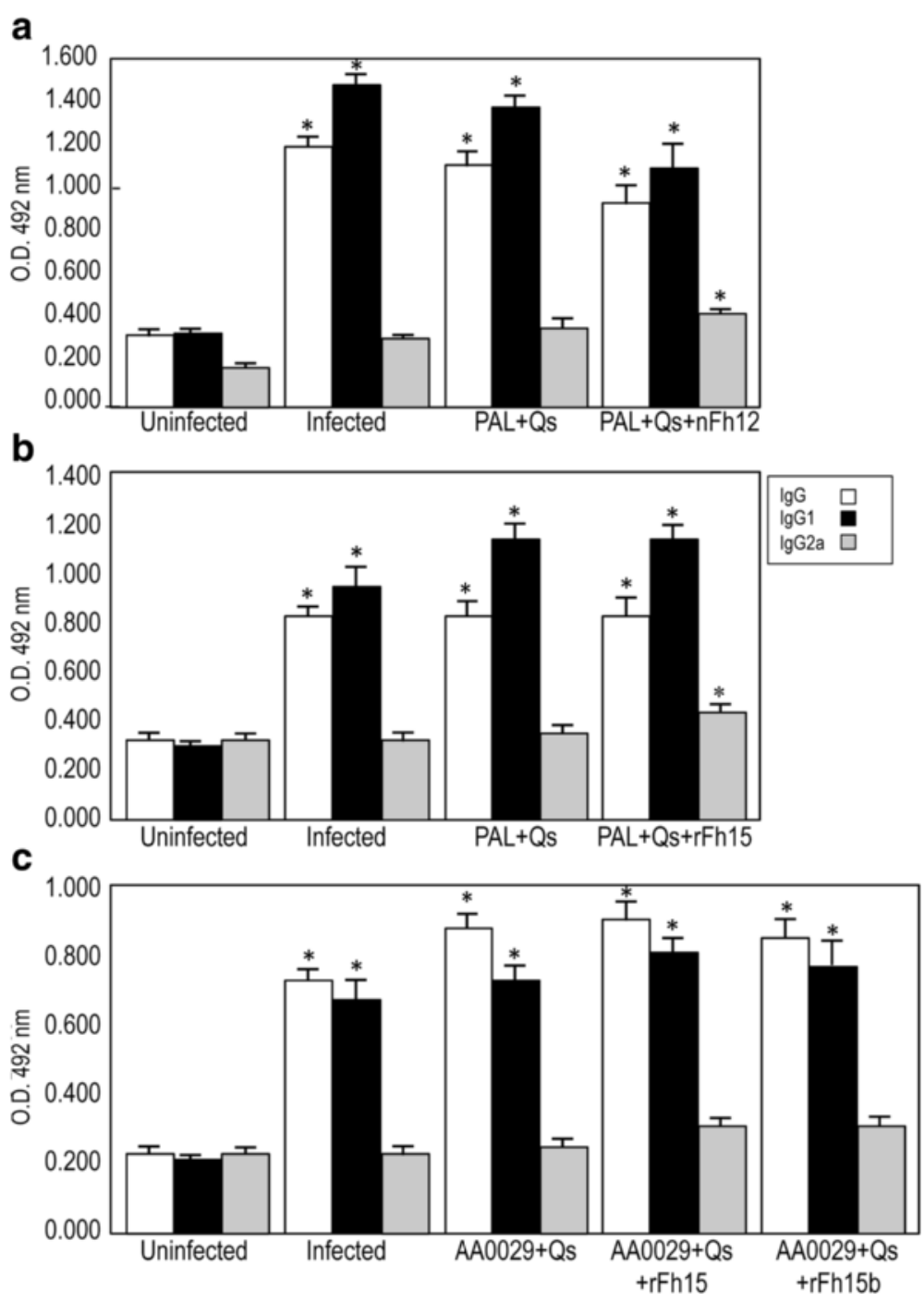

Fig. 4 Serum-specific lgG, IgG1 and IgG2a antibody levels by ELISA 8 weeks post-challenge against soluble adult worm antigens from S. mansoni (SoSbAWA). Data presented as the mean \pm standard error of the mean. BALB/c mice were vaccinated with their respective antigens formulated with the adjuvant adaptation (ADAD) vaccination system with the natural immunomodulator PAL or the synthetic AA0029 and challenged with 150 cercariae of S. mansoni. a Vaccination with PAL+Qs+nFh12+PAL; b Vaccination with PAL+Qs+rFh15; c vaccination using AA0029+Qs+rFh15 and AA0029+Qs+rFh15b. O.D., optical densities; ${ }^{*} P<0.05$ compared to uninfected controls

in terms of recovered females (44\%), eggs confined in liver (53\%), eggs in the gut (60\%) and hepatic lesions (75\%) However, no significant reduction was observed in the recovery of total and male adult parasites (Table 1, Fig. 2). Adjuvant controls treated with AA0029+Qs showed no protection against S. mansoni challenge (Table 1). A significantly higher production of specific anti-rFh15 and anti-rFh15b IgG was observed in the vaccinated group compared to the uninfected control group at the time of infection and at the end of the experiment particularly in mice vaccinated with rFh15 (Fig. 3c and Additional file 1: Table S1). Also all infected groups showed significant increase in of IgG, IgG1 against SoSmAWA 8 weeks post-infection but not IgG2a (Fig. 4c and Additional file 2: Table S2).

\section{Cell immune response induced by $\mathrm{rFh} 15$ and $\mathrm{rFh} 15 \mathrm{~b}$ using ADAD vaccination system with AA0029 as an immunomodulator}

Cytokine levels were measured in cultured splenocyte supernatants to analyse Th1, Th2, Treg and Th17 T-cell responses. It was observed that mice immunised with AA0029+Qs+rFh15 showed a significant increase in TNF $\alpha$, IL-6, IL-2 and IL-4 compared to untreated and adjuvant controls (Table 2). Similarly, mice treated with AA0029+Qs+rFh15b had high levels of TNF $\alpha$, IL-2 and IL-4 compared to untreated and adjuvant controls 
Table 2 Cytokine production (TNF-a, IL-6, IL-1a IFNy, IL-2, IL-4, IL-10, IL-17) in supernatants of splenocyte cultures in untreated BALB/ c mice, treated with AA0029+Qs and immunised with AA0029+Qs+rFh15 and AA0029+Qs+rFh15b 2 weeks after immunisation schedule. Data are presented as the mean \pm standard error of the mean. Kruskal-Wallis $X^{2}$, degrees of freedom $(d f)$ and $P$-values, and $P$-values in case of significant differences in pairwise comparisons

\begin{tabular}{|c|c|c|c|c|c|c|c|}
\hline \multirow[t]{2}{*}{ Cytokine } & \multirow{2}{*}{$\begin{array}{l}\text { Untreated } \\
(\mathrm{pg} / \mathrm{ml})\end{array}$} & \multirow{2}{*}{$\begin{array}{l}\text { AA0029+Qs } \\
(\mathrm{pg} / \mathrm{ml})\end{array}$} & \multirow{2}{*}{$\begin{array}{l}\text { AA0029+Qs+rFh15 } \\
(\mathrm{pg} / \mathrm{ml})\end{array}$} & \multirow{2}{*}{$\begin{array}{l}\text { AA0029+Qs+rFh15b } \\
(\mathrm{pg} / \mathrm{ml})\end{array}$} & \multicolumn{3}{|c|}{ Kruskal-Wallis } \\
\hline & & & & & $\overline{x^{2}}$ & $d f$ & $P$ \\
\hline \multirow[t]{2}{*}{ TNFa } & $313 \pm 98$ & $214 \pm 20$ & $937 \pm 130$ & $1,074 \pm 89$ & 16.22 & 3 & 0.001 \\
\hline & & & $P=0.001^{\mathrm{a}}$ & $P=0.001^{\mathrm{a}}$ & & & \\
\hline \multirow[t]{3}{*}{ IL-6 } & $964 \pm 118$ & $1,318 \pm 137$ & $2,755 \pm 226$ & $1,613 \pm 137$ & 17.11 & 3 & 0.001 \\
\hline & & & $P=0.001^{\mathrm{a}}$ & $P=0.001^{\mathrm{a}}$ & & & \\
\hline & & & & $P<0.001^{b}$ & & & \\
\hline IL-1a & $527 \pm 65$ & $368 \pm 32$ & $448 \pm 23$ & $581 \pm 142$ & & & \\
\hline \multirow[t]{3}{*}{ IFNY } & $543 \pm 35$ & $643 \pm 16$ & $735 \pm 23$ & $890 \pm 79$ & 20.40 & 3 & $<0.001$ \\
\hline & & & & $P<0.001^{a}$ & & & \\
\hline & & & & $P<0.001^{b}$ & & & \\
\hline \multirow[t]{2}{*}{ IL-2 } & $592 \pm 74$ & $774 \pm 84$ & $1,025 \pm 47$ & $888 \pm 41$ & 10.27 & 3 & 0.016 \\
\hline & & & $P<0.001^{\mathrm{a}}$ & $P=0.001^{\mathrm{a}}$ & & & \\
\hline \multirow[t]{2}{*}{$\mid \mathrm{L}-4$} & $1,138 \pm 101$ & $1,508 \pm 82$ & $2,078 \pm 145$ & $1,653 \pm 18$ & 16.91 & 3 & $<0.001$ \\
\hline & & & $P<0.001^{\mathrm{a}}$ & $P<0.001^{\mathrm{a}}$ & & & \\
\hline IL-10 & $481 \pm 46$ & $485 \pm 39$ & $424 \pm 7$ & $459 \pm 21$ & & & \\
\hline $\mathbb{I L}-17$ & $1,724 \pm 167$ & $2,048 \pm 43$ & $2,053 \pm 46$ & $1,988 \pm 268$ & & & \\
\hline
\end{tabular}

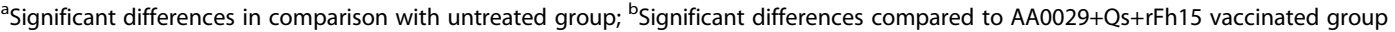

(Table 2). Additionally, we observed less IL-6 production and highly significant levels of IFN $\gamma$ than mice vaccinated with AA0029+Qs+rFh15 (see Table 2). We observed that untreated mice and adjuvant controls (PAL+Qs) showed similar cytokine patterns. Also, no differences were found in IL-17 and IL-10 cytokine levels in either rFh15- or rFh15b-immunised mice. Regarding the percentage of splenocyte populations, only mice vaccinated with AA0029+Qs+rFh15b showed a significant reduction in B220 cells compared with untreated and PAL+Qs treated animals (Table 3). No differences in $\mathrm{T}$ and $\mathrm{B}$ splenocyte population were observed between untreated mice and those treated with PAL+Qs.

\section{Differential antibody patterns in mice vaccinated with rFh15 vs rFh15b}

Antibody response of rFh15- and rFh15b-immunised mice were studied to understand the intensity of the humoral response elicited by the two recombinant proteins, due to the importance of antibodies in resistance to schistosomiasis and in an attempt to explain the differential protection observed between these molecules. Two weeks after the immunisation schedule, a significantly higher production of specific IgG, IgG1, IgG2a, IgM, IgE anti-rFh15 or anti-rFh15b was observed in $\mathrm{AA0029+Qs+rFh15}$ and in AA0029+Qs+rFh15b vaccinated mice respectively, compared to untreated controls

Table 3 Percentages of splenocyte populations (CD45, CD4, CD8, CD197, CD62L, CD27, B220) in untreated BALB/C mice, treated with AA0029+Qs and immunised with AA0029+Qs+rFh15 and AA0029+Qs+rFh15b 2 weeks after immunisation schedule. Data presented as the mean \pm standard error of the mean

\begin{tabular}{|c|c|c|c|c|}
\hline Cell population & $\begin{array}{l}\text { Untreated } \\
(\%)\end{array}$ & $\begin{array}{l}\text { AA0029+Qs } \\
(\%)\end{array}$ & $\begin{array}{l}\text { AA0029+Qs+rFh15 } \\
(\%)\end{array}$ & $\begin{array}{l}\text { AA0029+Qs+rFh15b } \\
\text { (\%) }\end{array}$ \\
\hline CD45 & $75.7 \pm 3.4$ & $77.0 \pm 0.7$ & $75.5 \pm 2.8$ & $66.7 \pm 1.3$ \\
\hline CD4 & $21.1 \pm 1.3$ & $20.7 \pm 0.4$ & $21.3 \pm 0.5$ & $21.7 \pm 4.0$ \\
\hline CD8 & $8.4 \pm 0.5$ & $8.4 \pm 0.6$ & $10.2 \pm 0.6$ & $9.5 \pm 1.3$ \\
\hline CD197 & $16.9 \pm 1.7$ & $18.0 \pm 2.1$ & $12.6 \pm 2.8$ & $14.9 \pm 0.6$ \\
\hline CD62L & $23.2 \pm 3.2$ & $20.1 \pm 5.0$ & $17.2 \pm 0.9$ & $15.2 \pm 5.0$ \\
\hline CD27 & $19.4 \pm 1.9$ & $18.0 \pm 1.6$ & $16.9 \pm 0.8$ & $16.7 \pm 3.6$ \\
\hline B220 & $35.9 \pm 3.2$ & $39.4 \pm 0.6$ & $23.2 \pm 1.7$ & $21.3 \pm 0.7^{*}$ \\
\hline
\end{tabular}

*Significant differences in comparison with untreated group $P<0.001$ (Kruskal-Wallis $X^{2}=15.51, d f=3, P=0.001$ ) 


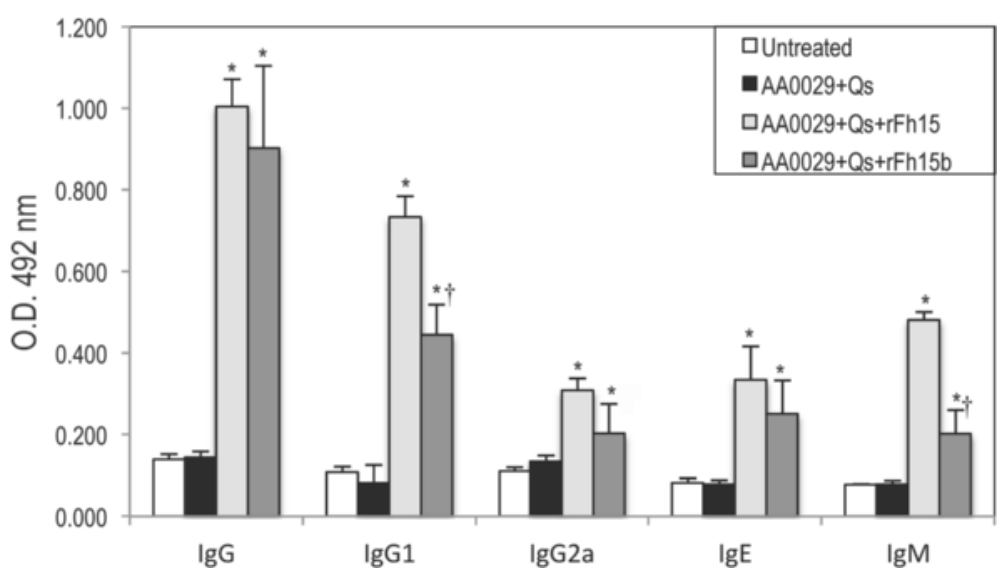

Fig. 5 Antibody detection (IgG, IgG1, IgG2a, IgE and IgM) against rFh15 or rFh15b 2 weeks after immunisation schedule in BALB/c mice. Data presented as the mean \pm standard error of the mean. Groups: Untreated; Treated with AA0029+Qs; Immunised with AA0029+Qs + rFh15; and Immunised with AA0029+Qs+rFh15b. O.D., optical density; ${ }^{*} P<0.05$ in comparison with untreated controls and treated with AA0029+Qs;

${ }^{\dagger} P<0.05$ compared to mice treated with AA0029+Qs+rFh15

(Fig. 5 and Additional file 3: Table S3). Furthermore, we observed significantly higher levels of IgG1 and IgM in mice vaccinated with $\mathrm{rFh} 15$ than mice vaccinated with rFh15b (Fig. 5 and Additional file 3: Table S3).

\section{Discussion}

A significant effort has been focused on schistosomiasis vaccine development because of its potential ability to control or eradicate the disease. FABP from $F$. hepatica have demonstrated a valuable cross-protection against $S$. bovis in experimental models [20-23]; similar effects were reported for FABP of $14.6 \mathrm{kDa}$ from F. gigantica [24]. Also, the S. mansoni FABP Sm14 have reached Phase I studies [19]. However, the immunoprotective potential of $F$. hepatica FABPs has not been tested against $S$. mansoni infection until now. In this study, we present the immunoprotective potential of FABP obtained from $F$. hepatica represented by the native form (nFh12) and two recombinants (rFh15, rFh15b) against the $S$. mansoni infection in BALB/c mice. These molecules have been expressed in prokaryotic and eukaryotic systems. The inbred mice have a biased Th2 genetic background, resembling the immunological profile observed in people living in endemic areas [36]. In this study, we used the adjuvant adaptation (ADAD) vaccination system using natural (PAL) and synthetic (AA0029) immunomodulators developed by our research group for vaccination against fasciolosis and schistosomiasis to improve limitations of the classical Freund's adjuvant [27, 30, 35, 37].

We observed a high protection in terms of worm recovery, eggs trapped in the tissues and hepatic damage in mice vaccinated with the native $\mathrm{nFh} 12$ and the $E$. coli recombinant $\mathrm{rFh} 15$. These results are close to those obtained by vaccination against $S$. bovis with both antigens formulated in ADAD vaccination system with PAL as well as AA0029 [22, 23]. Our results are also comparable to those shown using the FABP Sm14 obtained from $S$. mansoni in experimental models [16] or using the $F$. gigantica $14.6 \mathrm{kDa}$ molecule [24]. Taken together, these results reinforce the value of FABPs in schistosomiasis vaccination development. We observed a high production of specific IgG by ELISA against the three antigens used for vaccination, indicating an intense immunological response. A vigorous humoral response is found in natural resistance to infection possessed by people living in hyperendemic areas [36, 38, 39] and experimental models [40]. Also, vaccinated animals generated high levels in both IgG and IgG1 against SoSmAWA 8 weeks post-challenge, but there was significant production of IgG2a only using the natural immunomodulator PAL. This effect has been observed in previous studies related to the use of PAL in vaccination against $F$. hepatica and $S$. bovis and its association with protection and downregulation of the dominant Th2 established in schistosomes or F. hepatica infections [22, 23, 41, 42]. An appropriate adjuvant system able to induce an adequate immune response is recognised as an important tool for developing vaccines. A good feature is the specific adjuvant activity driving the immunological response together with the antigen [36, 43]. We did not find any protection induced in mice treated either with PAL+Qs or AA0029+Qs after challenge with S. mansoni when compared with infection controls. This indicates the specific activity of both adjuvants in our experiments.

Additionally, we observed that the antigen obtained using baculovirus as vector ( $\mathrm{rFh} 15 \mathrm{~b}$ ) formulated with AA0029 in ADAD showed high reductions of eggs in the tissues and liver damage, but there were only small, nonsignificant reductions in total worm burden compared to AA0029+Qs+rFh15-vaccinated mice after the challenge. 
Then we studied the immune response induced with rFh15 and rFh15b using the synthetic immunomodulator AA0029 along E. coli recombinant $\mathrm{rFh} 15$ in the ADAD vaccination system. We observed that it promoted an early potent mixed Th1/Th2 pro-inflammatory immune response with significant production of TNF $\alpha$, IL-6, IL-2, IL-4 and high level of specific antibodies. All of this could explain the protection against $S$. mansoni challenge as pointed out in previous studies of experimental protection against $F$. hepatica and S. bovis using AA0029 formulated in ADAD [23, 35, 36]. Vaccination with the protein produced in $T . n i$ (AA0029+Qs+rFh15b) showed high levels of TNF $\alpha$, IL-6, IFNY IL-2, IL-4 and antibodies, but there was a reduction in B220 cells percentage compared to untreated mice. Moreover, we observed less IL-6, IgG1 and IgM in these mice compared to those immunised with AA0029+Qs+rFh15. This indicates a potent pro-inflammatory and Th1/Th2 mixed response with an impairment of humoral response involving B memory cells and immunoglobulins that could be responsible for the low protection in terms of worm recovery [44]. Another possible explanation of the differences in protection could be the post-translational modifications that occur in the different expression systems involving glycosylation and the fact that only one isoform was used [45].

\section{Conclusions}

In conclusion, our data demonstrated the ability of FAPB obtained from $F$. hepatica to induce protection against infections with $S$. mansoni in BALB/c mice. Also the use of PAL seems to induce an increase in Th1-like immune response during infection. ADAD formulation with the immunomodulator AA0029 showed an intense proinflamatory and mixed Th1/Th2 immune response. These molecules may have valuable effects leading to reduction of pathology and transmission of the disease. Our results warrant further studies in other animal models closer to humans to state the actual protection ability of FABP against $S$. mansoni infection.

\section{Additional files}

Additional file 1: Table S1. Statistical information to Fig. 3. ANOVA $F$ and $P$ values, and post-hoc Tukey's honest significance test $P$ values of significant increases in lgG against rFh12, rFh15 or rFh15b antigens in vaccinated BALB/C mice using natural and recombinant FABP (nFh12, rFh15 or rFh15b) formulated with the adjuvant adaptation (ADAD) vaccination system with the natural immunomodulator PAL or the synthetic AA0029 compared to untreated control group. (DOCX $17 \mathrm{~kb}$ )

Additional file 2: Table S2. Statistical information to Fig. 4. ANOVA $F$ and $P$ values, and post-hoc Tukey's honest significance test $P$ values of significant increases in $\operatorname{lgG}, \operatorname{lgG} 1, \lg G 2$ a against SoSmAWA antigen in vaccinated BALB/C mice using natural and recombinant FABP (nFh12, rFh15 or rFh15b) formulated with the adjuvant adaptation (ADAD) vaccination system with the natural immunomodulator PAL or the synthetic AA0029 compared to untreated control group. (DOCX $19 \mathrm{~kb}$ )
Additional file 3: Table S3. Complementary statistical information to Fig. 5. Kruskal-Wallis $X^{2}$ degrees of freedom $(d f)$ and $P$-values, and comparison in pairs $P$ values of significant differences in $\lg G, \lg G 1$, IgG2a, $\lg E$ and $\lg M$ production against SoSmAWA antigen in vaccinated mice compared to untreated control group at week six of the experiment. (DOCX $16 \mathrm{~kb}$ )

\section{Abbreviations}

ADAD: Adjuvant adaptation vaccination system; ANOVA: analysis of variance; FABP: fatty acid binding proteins; nFh12: native FABP of $12 \mathrm{kDa}$; Qs: non haemolytic saponines from Quillaja saponaria; rFh 15: recombinant FABP of $15 \mathrm{kDa}$ expressed in Escherichia coli; rFh15b: recombinant FABP of $15 \mathrm{kDa}$ expressed in Trichoplusia ni; SoSmAWA: soluble adult worm antigens from schistosoma mansoni.

\section{Competing interests}

The authors declare that they have no competing interest. Sponsors had no role in study design, or collection, analysis and interpretation of data.

\section{Authors' contributions}

$B V, J L-A$ and $A M$, conceived and designed the study. BV, JL-A, JR-C and EO performed the experiments. BV, JL-A, JR-C PF-S and AM analysed the data. BV JR-C and JL-A drafted the first draft of the manuscript. AM critically revised the manuscript. All authors read and approved the final manuscript.

\section{Acknowledgements}

This research was supported by Proyectos Integrados IBSAL (IBY15/00003; Salamanca, Spain), and RICET VI PN I+D+| 2008-2011, ISCIII FEDER (RD12/ 0018/0002) and the Government of Spain. Banco de Santander supported JRC. We are grateful to ASAC Pharmaceutical International AIE (Alicante, Spain) for kindly providing PAL, to D.J. Lora Sanz (Safic-Alcan España S.L.) and SEPPIC (Barcelona, Spain) for providing Montanide ISA 763A GV and to G.V. Hillyer for providing the native nFh12 protein. We also acknowledge the support of Manasa Bhatta (Emory University) for the English edition and the editorial help for the style correction.

\section{Author details}

${ }^{1}$ Parasite and Molecular Immunology Laboratory, Tropical Disease Research Centre, Universidad de Salamanca (IBSAL-CIETUS), Avda. Licenciado Méndez Nieto s/n, 37007 Salamanca, Spain. ${ }^{2}$ Department of Pharmaceutical Chemistry, Faculty of Pharmacy, University of Salamanca, IBSAL-CIETUS, Salamanca, Spain. ${ }^{3}$ Present address: Centro de Investigación en Salud para el Trópico (CIST), Carretera Troncal del Caribe, Sector Mamatoco, Santa Marta, Magdalena, Colombia. ${ }^{4}$ Present address: Facultad de Medicina, Universidad Cooperativa de Colombia, Carretera Troncal del Caribe, Sector Mamatoco, Santa Marta, Magdalena, Colombia.

Received: 19 November 2015 Accepted: 7 April 2016

Published online: 18 April 2016

References

1. WHO Schistosomiasis: number of people treated worldwide in 2013. Wkly Epidemiol Rec. 2015;90:25-32.

2. Cioli D, Pica-Mattoccia L, Basso A, Guidi A. Schistosomiasis control: praziquantel forever? Mol Biochem Parasitol. 2014;195:23-9.

3. Greenberg RM. New approaches for understanding mechanisms of drug resistance in schistosomes. Parasitology. 2013;140:1534-46.

4. Pérez del Villar L, Burguillo FJ, López-Abán J, Muro A. Systematic review and meta-analysis of artemisinin based therapies for the treatment and prevention of schistosomiasis. PLoS One. 2012;7:e45867.

5. Liu YX, Wu W, Liang YJ, Jie ZL, Wang H, Wang W, Huang YX. New uses for old drugs: the tale of artemisinin derivatives in the elimination of schistosomiasis japonica in China. Molecules. 2014;19:15058-74.

6. Grimes JE, Croll D, Harrison WE, Utzinger J, Freeman MC, Templeton MR. The roles of water, sanitation and hygiene in reducing schistosomiasis: a review. Parasit Vectors. 2015;8:156.

7. El Ridi R, Othman AA, McManus DP. Editorial: the schistosomiasis vaccine - it is time to stand up. Front Immunol. 2015;6:390.

8. Fukushige M, Mitchell KM, Bourke CD, Woolhouse ME, Mutapi F. A Metaanalysis of experimental studies of attenuated Schistosoma mansoni vaccines in the mouse model. Front Immunol. 2015;6:85. 
9. McWilliam HE, Driguez P, Piedrafita D, McManus DP, Meeusen EN. Novel immunomic technologies for schistosome vaccine development. Parasite Immunol. 2012;34:276-84.

10. Fonseca $C T$, Braz Fiqueiredo Carvalho G, Carvalho Alves C, de Melo TT. Schistosoma tegument proteins in vaccine and diagnosis development: an update. J Parasitol Res. 2012;2012:541268.

11. Figueiredo BC, Ricci ND, de Assis NR, de Morais SB, Fonseca CT, Oliveira SC. Kicking in the Guts: Schistosoma mansoni Digestive Tract Proteins are Potential Candidates for Vaccine Development. Front Immunol. 2015;6:22.

12. Riveau G, Deplanque D, Remoué F, Schacht AM, Vodougnon H, Capron M, Thiry M, Martial J, Libersa C, Capron A. Safety and immunogenicity of rSh28GST antigen in humans: phase 1 randomized clinical study of a vaccine candidate against urinary schistosomiasis. PLoS Negl Trop Dis. 2012;6:e1704

13. Chemale G, Perally S, LaCourse EJ, Prescott MC, Jones LM, Ward D, Meaney M, Hoey E, Brennan GP, Fairweather I, Trudgett A, Brophy PM. Comparative proteomic analysis of triclabendazole response in the liver fluke Fasciola hepatica. J Proteome Res. 2010;9:4940-51.

14. Cwiklinski K, Dalton JP, Dufresne PJ, La Course J, Williams DJ, Hodgkinson J, Paterson S. The Fasciola hepatica genome: gene duplication and polymorphism reveals adaptation to the host environment and the capacity for rapid evolution. Genome Biol. 2015;16:71

15. Marcilla A, Trelis M, Cortés A, Sotillo J, Cantalapiedra F, Minguez MT, Valero ML, Sánchez del Pino MM, Muñoz-Antoli C, Toledo R, Bernal D. Extracellular vesicles from parasitic helminths contain specific excretory/secretory proteins and are internalized in intestinal host cells. PLoS One. 2012;7(9): e45974

16. Tendler M, Almeida M, Simpson A. Development of the Brazilian antischistosomiasis vaccine based on the recombinant fatty acid binding protein Sm14 plus GLA-SE adjuvant. Front Immunol. 2015;6:218.

17. Hillyer GV. Comparison of purified $12 \mathrm{kDa}$ and recombinant $15 \mathrm{kDa}$ Fasciola hepatica antigens related to a Schistosoma mansoni fatty acid binding protein. Mem Inst Oswaldo Cruz. 1995;90:249-53.

18. Hillyer GV. Fasciola antigens as vaccines against fascioliasis and schistosomiasis. J Helminthol. 2005;79:241-7.

19. Mossallam SF, Amer El, Ewaisha RE, Khalil AM, Aboushleib HM, Bahey-El-Din M. Fusion protein comprised of the two schistosomal antigens, Sm14 and Sm29, provides significant protection against Schistosoma mansoni in murine infection model. BMC Infect Dis. 2015;15:147.

20. Abán JL, Ramajo V, Arellano JL, Oleaga A, Hillyer GV, Muro A. A fatty acid binding protein from Fasciola hepatica induced protection in C57/BL mice from challenge infection with Schistosoma bovis. Vet Parasitol. 1999;83:107-21.

21. Abáné $J$, Oleaga A, Ramajo V, Casanueva P, Arellano JL, Hillyer GV, Muro A. Vaccination of mice against Schistosoma bovis with a recombinant fatty acid binding protein from Fasciola hepatica. Vet Parasitol. 2000;91:33-42.

22. Vicente B, López-Abán J, Rojas-Caraballo J, Pérez del Villar L, Hillyer GV Martínez-Fernández AR, Muro A. A Fasciola hepatica-derived fatty acid binding protein induces protection against schistosomiasis caused by Schistosoma bovis using the adjuvant adaptation (ADAD) vaccination system. Exp Parasitol. 2014;145:145-51.

23. Vicente B, López-Abán J, Rojas-Caraballo J, del Olmo E, Fernández-Soto P, Ramajo-Martín V, Muro A. The combination of the aliphatic diamine AA0029 in ADAD vaccination system with a recombinant fatty acid binding protein could be a good alternative for the animal schistosomiasis control. Exp Parasitol. 2015;154:134-42.

24. Rabia Aly I, Diab M, El-Amir AM, Hendawy M, Kadry S. Fasciola gigantica fatty acid binding protein (FABP) as a prophylactic agent against Schistosoma mansoni infection in CD1 mice. Korean J Parasitol. 2012;50:37-43.

25. Sokolenko S, George S, Wagner A, Tuladhar A, Andrich JM, Aucoin MG. Coexpression vs. co-infection using baculovirus expression vectors in insect cell culture: Benefits and drawbacks. Biotechnol Adv. 2012;30:766-81.

26. Barford D, Takagi Y, Schultz P, Berger I. Baculovirus expression: tackling the complexity challenge. Curr Opin Struct Biol. 2013;23:357-64.

27. Martínez-Fernández AR, Nogal-Ruiz JJ, López-Abán J, Ramajo V, Oleaga A, Manga-González Y, Hillyer GV, Muro A. Vaccination of mice and sheep with Fh12 FABP from Fasciola hepatica using the new adjuvant/immunomodulator system ADAD. Vet Parasitol. 2004;126:287-98.

28. López-Abán J, Esteban A, Vicente B, Rojas-Caraballo J, del Olmo E, MartínezFernández AR, Hillyer GV, Muro A. Adaptive immune stimulation is required to obtain high protection with fatty acid binding protein vaccine candidate against Fasciola hepatica in BALB/C mice. J Parasitol. 2012;98:527-35.
29. del Olmo E, Plaza A, Muro A, Martínez-Fernández AR, Nogal-Ruiz JJ, LópezPérez JL, Feliciano AS. Synthesis and evaluation of some lipidic aminoalcohols and diamines as immunomodulators. Bioorg Med Chem Lett. 2006;16:6091-5.

30. Uribe N, Muro A, Vieira C, López-Abán J, del Olmo E, Suárez L, MartínezFernández AR, Siles-Lucas M. Genetic and immunological characterization of the 14-3-3 molecule from Schistosoma bovis. J Parasitol. 2007:93:964-9.

31. Charan J, Kantharia ND. How to calculate sample size in animal studies? J Pharmacol Pharmacother. 2013;4:303-6.

32. Festing MF, Altman DG. Guidelines for the design and statistical analysis of experiments using laboratory animals. ILAR J. 2002;43:244-58.

33. Rodríguez-Pérez J, Rodríguez-Medina JR, García-Blanco MA, Hillyer GV. Fasciola hepatica: molecular cloning, nucleotide sequence, and expression of a gene encoding a polypeptide homologous to a Schistosoma mansoni fatty acid-binding protein. Exp Parasitol. 1992;74:400-7.

34. Schneider CA, Rasband WS, Eliceiri KW. NIH Image to ImageJ: 25 years of image analysis. Nat Methods. 2012;9:671-5.

35. Rojas-Caraballo J, López-Abán J, Pérez del Villar L, Vizcaíno C, Vicente B, Fernández-Soto P, del Olmo E, Patarroyo MA, Muro A. In vitro and in vivo studies for assessing the immune response and protection-inducing ability conferred by Fasciola hepatica-derived synthetic peptides containing B- and T-cell epitopes. PLoS One. 2014;9:e105323.

36. Alves CC, Araujo N, dos Santos VC, Couto FB, Assis NR, Morais SB, Oliveira SC, Fonseca CT. Sm29, but not Sm22.6 retains its ability to induce a protective immune response in mice previously exposed to a Schistosoma mansoni infection. PLoS Negl Trop Dis. 2015;9:e0003537.

37. Siles-Lucas M, Uribe N, López-Abán J, Vicente B, Orfao A, Nogal-Ruiz JJ, Feliciano AS, Muro A. The Schistosoma bovis Sb14-3-3zeta recombinant protein cross-protects against Schistosoma mansoni in BALB/C mice. Vaccine. 2007;25:7217-23.

38. McManus DP, Loukas A. Current status of vaccines for schistosomiasis. Clin Microbiol Rev. 2008;21:225-42.

39. Melo TT, Sena IC, Araujo N, Fonseca $C T$. Antibodies are involved in the protective immunity induced in mice by Schistosoma mansoni schistosomula tegument (Smteg) immunization. Parasite Immunol. 2014;36:107-11.

40. El-Shabasy EA, Reda ES, Abdeen SH, Said AE, Ouhtit A. Transmission electron microscopic observations on ultrastructural alterations in Schistosoma mansoni adult worms recovered from C57BL/6 mice treated with radiation-attenuated vaccine and/or praziquantel in addition to passive immunization with normal and vaccinated rabbit sera against infection. Parasitol Res. 2015;114:1563-80.

41. López-Abán J, Nogal-Ruiz JJ, Vicente B, Morrondo P, Diez-Baños P, Hillyer GV, Martínez-Fernández AR, Feliciano AS, Muro A. The addition of a new immunomodulator with the adjuvant adaptation ADAD system using fatty acid binding proteins increases the protection against Fasciola hepatica. Vet Parasitol. 2008:153:176-81.

42. López-Abán J, Casanueva P, Nogal J, Arias M, Morrondo P, Diez-Baños P, Hillyer GV, Martínez-Fernández AR, Muro A. Progress in the development of Fasciola hepatica vaccine using recombinant fatty acid binding protein with the adjuvant adaptation system ADAD. Vet Parasitol. 2007;145:287-96.

43. Stephenson R, You H, McManus DP, Toth I. Schistosome vaccine adjuvants in preclinical and clinical research. Vaccines (Basel). 2014;2:654-85.

44. Rodig SJ, Shahsafaei A, Li B, Dorfman DM. The CD45 isoform B220 identifies select subsets of human B cells and B-cell lymphoproliferative disorders. Hum Pathol. 2005:36:51-7.

45. Lu HY, Chen YH, Liu HJ. Baculovirus as a vaccine vector. Bioengineered. 2012;3:271-4.

\section{Submit your next manuscript to BioMed Central and we will help you at every step:}

- We accept pre-submission inquiries

- Our selector tool helps you to find the most relevant journal

- We provide round the clock customer support

- Convenient online submission

- Thorough peer review

- Inclusion in PubMed and all major indexing services

- Maximum visibility for your research

Submit your manuscript at www.biomedcentral.com/submit 